Purdue University Purdue e-Pubs

2012

\title{
Numerical Investigation of an Evaporating Meniscus in a Channel
}

\author{
H. K. Dhavaleswarapu \\ Purdue University \\ J. Y. Murthy \\ Purdue University \\ S V. Garimella \\ Purdue University, sureshg@purdue.edu
}

Follow this and additional works at: http://docs.lib.purdue.edu/coolingpubs

Dhavaleswarapu, H. K.; Murthy, J. Y.; and Garimella, S V., "Numerical Investigation of an Evaporating Meniscus in a Channel" (2012). CTRC Research Publications. Paper 162.

http://dx.doi.org/10.1016/j.ijheatmasstransfer.2011.10.017

This document has been made available through Purdue e-Pubs, a service of the Purdue University Libraries. Please contact epubs@purdue.edu for additional information. 


\title{
Numerical Investigation of an Evaporating Meniscus in a Channel ${ }^{\S}$
}

\author{
Hemanth K. Dhavaleswarapu, Jayathi Y. Murthy and Suresh V. Garimella \\ School of Mechanical Engineering and Birck Nanotechnology Center \\ Purdue University, West Lafayette, IN 47907-2088 USA
}

\begin{abstract}
A detailed numerical model is developed that describes heat and mass transfer from a meniscus to open air. The model accounts for the effects of evaporation at the interface, vapor transport through air, thermocapillary convection, and natural convection in air. Evaporation at the interface is modeled using kinetic theory, while vapor transport in air is computed by solving the complete species transport equation. Since the vapor pressure at the liquid-gas interface depends on both evaporation and the vapor transport in air, the equations are solved in an iterative manner. Evaporation is strongest at the triple line due to the highest local vapor diffusion gradient in this region. This differential evaporation, coupled with the low thermal resistance near the triple line, results in a temperature gradient along the interface that creates thermocapillary convection. The numerical results obtained show satisfactory agreement with experimental data for the evaporation rate and the temperature profile. Additionally, results from a simplified model neglecting thermocapillary convection are compared with the full solution, thus delineating the importance of thermocapillary convection-induced mixing in the energy transfer process. The present generalized model may easily be extended to other geometries and hence may be used in the design of two-phase cooling devices.
\end{abstract}

Keywords: Evaporation, Diffusion, Meniscus, Thin film, Thermocapillary, Marangoni.

\footnotetext{
${ }^{\S}$ Submitted for possible publication in International Journal of Heat and Mass Transfer, January 2011 and in revised form September 2011
} 


\section{NOMENCLATURE}

\begin{tabular}{|c|c|c|c|}
\hline$A$ & area $\left(\mathrm{m}^{2}\right)$ & Greek & \\
\hline$C$ & $\begin{array}{l}\text { species molar concentration } \\
\left(\mathrm{mol} / \mathrm{m}^{3}\right)\end{array}$ & $\beta$ & thermal expansion coefficient $(1 / \mathrm{K})$ \\
\hline$D$ & diffusion coefficient in air $\left(\mathrm{m}^{2} / \mathrm{s}\right)$ & $\mu$ & dynamic viscosity $\left(\mathrm{N} \mathrm{s} / \mathrm{m}^{2}\right)$ \\
\hline$G r$ & Grashof number & $\rho$ & density $\left(\mathrm{kg} / \mathrm{m}^{3}\right)$ \\
\hline$Q$ & heat dissipation $(\mathrm{W})$ & $\sigma$ & surface tension coefficient $(\mathrm{N} / \mathrm{m})$ \\
\hline$h_{f g}$ & latent heat of evaporation ( $\mathrm{J} / \mathrm{kg}$ ) & $\bar{\sigma}$ & accommodation coefficient \\
\hline$k$ & thermal conductivity ( $\mathrm{W} / \mathrm{m} \mathrm{K}$ ) & Subscript & \\
\hline$\dot{m}$ & mass flow rate $(\mathrm{kg} / \mathrm{s})$ & $n$ & normal direction \\
\hline$m^{\prime \prime}$ & $\operatorname{mass}$ flux $\left(\mathrm{kg} / \mathrm{m}^{2} \mathrm{~s}\right)$ & air & air \\
\hline $\bar{M}$ & molecular weight ( $\mathrm{kg} / \mathrm{kmol})$ & $e q u$ & equilibrium \\
\hline$p$ & pressure $\left(\mathrm{N} / \mathrm{m}^{2}\right)$ & $g$ & gas ( vapor/air mixture ) \\
\hline $\bar{R}$ & universal gas constant ( $\mathrm{J} / \mathrm{mol} \mathrm{K}$ ) & $l$ & liquid \\
\hline$T$ & temperature ( $\mathrm{K}$ ) & $l v$ & interface \\
\hline$w$ & channel spacing $(\mu \mathrm{m})$ & out & outlet \\
\hline$V$ & fluid velocity $(\mathrm{m} / \mathrm{s})$ & ref & reference \\
\hline \multirow[t]{6}{*}{$\kappa$} & Thermal diffusivity $\left(\mathrm{m}^{2} / \mathrm{s}\right)$ & sat & saturated \\
\hline & & $v$ & vapor \\
\hline & & vapor/air & vapor - air region \\
\hline & & inlet & liquid inlet \\
\hline & & atm & atmosphere \\
\hline & & $\begin{array}{l}\text { sensible } \\
\text { heat }\end{array}$ & sensible heat of liquid \\
\hline
\end{tabular}




\section{INTRODUCTION}

Techniques exploiting evaporation heat transfer are attractive because of the significant increases in heat transport that can be realized by means of latent heat exchange. Heat pipes, vapor chambers and thermosyphons are examples of two-phase devices that are used in electronics cooling and other thermal engineering applications where the evaporated vapor is transferred primarily by convection in the vapor space. Diffusion-controlled transport of vapor into vapor/air mixtures is also of industrial significance in problems involving falling films and drying applications [1].

The efficiency of heat spreading in heat pipes and vapor chambers relies on the wick structure, the details of which determine the efficiency of heat removal by evaporation as well as the heat fluxes that can be supported by the amount of liquid supplied through capillary transport. In the wick structure of these two-phase devices, an evaporating meniscus is fundamentally responsible for heat transport. Thin-film evaporation, which takes place in a few $\mu \mathrm{m}$ long region near a solidliquid-vapor junction, has long been believed to be the dominant mode of heat transfer in such systems [2]. The efficacy of heat transfer in thin films is attributed to a high disjoining pressure gradient [3] which results in liquid being pulled into the thin-film region, as well as the very low thermal resistance resulting from the small film thickness. The intensive evaporation near the triple line creates a temperature gradient along the meniscus. This results in a surface tension gradient that gives rise to thermocapillary convection. Both the evaporation from the thin film as well as the thermocapillary convection induced have been reported in the literature $[4,5]$ to play a major role in the total heat transferred. However, the exact role and nature of these processes is still not completely understood. In drying from porous media, film curvature in the pores has been noted to cause more intensive evaporation to occur near the film tips than at other locations along the meniscus [1]. Differential evaporation along an interface is thus widely prevalent in diverse evaporation systems.

Wayner and co-workers [6] carried out extensive theoretical and experimental studies in this field and delineated several important factors influencing thin-film evaporation. Researchers $[7,8]$ have attributed as much as $90 \%$ of heat transfer to the thin-film region. However, Park and Lee [9] suggested that the thin-film contributed less than $5 \%$ of total heat transfer due to its small geometrical extent. Xu and Carey [7] developed an approximate model for meniscus evaporation in a V-groove. They assumed that heat transfer occurs only through the thin-film region and developed a model whose results were in reasonable agreement with their experiment. Stephan and Busse [10] developed a model based only on conduction to describe the heat and mass 
transport in the microregion of the meniscus in a V-groove. Dasgupta et al. [11] studied a 2D extended meniscus of heptane using ellipsometry and found high mass fluxes in the thin-film region using a semi-empirical model. However, their model neglected vapor diffusion effects. All the above models are conduction-based models and in which the effects of liquid flow were neglected.

Khrustalev and Faghri [12] presented a detailed mathematical model that described heat transfer from an evaporating meniscus in a capillary slot with a consideration of the liquid flow. They showed that this liquid flow resulted in an increase of $30 \%$ in the heat transfer coefficient. Jiang et al. [13] carried out experiments on a thin film on a cylinder exposed to air; a semiempirical model indicated that nearly $20-40 \%$ of the heat transfer occurs through the thin-film region. Rice and Faghri [14] developed a new interface tracking method to study the evaporation of a meniscus in a tube and achieved quantitative and qualitative agreement with experimental data. However, this model did not take into account the established kinetic theory expression for evaporation. Ruiz and Black [15] conducted a numerical analysis of the evaporation process of small water droplets of diameters less than $1 \mathrm{~mm}$ on heated surfaces. They were the first to model the internal fluid motion due to thermocapillary convection in droplets. They found that fluid motion significantly affects the thermal field in the droplet and concluded that a model without fluid motion underpredicts the evaporation rates. More recently, Strotos et al. [16] conducted a numerical study of evaporation of droplets impinging on heated surfaces using a modified volume-of-fluid (VOF) methodology and obtained good agreement with experimental results.

Current two-phase evaporator designs are often plagued with large thermal resistances, primarily because the wicks have not been fully optimized. Early models seem to have made either simplifying assumptions or are semi-empirical in nature. A comprehensive and experimentally validated model would significantly improve our understanding of the underlying physics and advance the design of wick structures in two-phase devices.

In an earlier paper [17], the authors described a novel test setup for studying thin-film evaporation effects in an evaporating meniscus subjected to a constant heat flux. The fluid lost to evaporation was replenished in the setup using a syringe pump to achieve a constant evaporation rate and also a steady meniscus. The meniscus images were obtained using a high resolution goniometer $(\sim 4 \mu \mathrm{m})$, and a high-end, science-grade IR camera was used for temperature measurements. The test setup allowed for temperature measurements to be made right at the triple line. Owing to the small working distance of the IR camera, experiments were conducted under open-to-air conditions. The test setup was isolated from external disturbances by means of 
a large enclosure. However, some air flow was still present in the surroundings of the test setup due to the air ventilation system in the laboratory because of breaks in the enclosure for camera access. The experimental parameters varied in this test setup were applied heat flux, liquid supply rate and channel width. The meniscus was found to attain a unique shape for each different combination of these parameters. It was found that the liquid-vapor interfacial area increased with a decrease in heat flux and an increase in evaporation rate, and remained unaffected by small changes in channel width. Microscale infrared thermography revealed a distinct temperature drop at the triple line indicating the effectiveness of thin-film heat transfer. This temperature drop was found to increase with increasing heat flux.

The objective of the present work is to develop a generalized model for an evaporating meniscus in an air ambient where both diffusion and convection in the air are important. The modeling approach presented in Wang et al. [18] forms the starting point for this work. The earlier model accounts for evaporation at the interface and diffusion through the air domain. Here the meniscus is assumed to be static as it is fed continuously. Menisci formed in a channel with a spacing $w$ of $500 \mu \mathrm{m}$ subjected to similar ambient conditions are considered in this work. Hence, the meniscus profile is assumed to be only a function of the liquid feeding rate and the applied heat flux. The meniscus profile and heat flux are used as inputs to the model and the predicted evaporation rate and temperature profile are compared to the experimental results. The model is validated against three experimental cases, each subjected to a different combination of applied heat flux and liquid feeding rate; all other conditions remain unchanged. Fig. 1 shows three such combinations of experimentally obtained meniscus images with case 1 and case 3 corresponding to the low and high heat fluxes studied, respectively. Unless otherwise stated, the majority of the results presented are for the intermediate heat flux case 2 . The role of thermocapillary convection in determining the heat transfer performance is also elucidated using the model. This experimentally validated numerical modeling framework can contribute to the improved design of two-phase cooling devices.

\section{MATHEMATICAL MODELING}

\subsection{Problem Description}

An evaporating heptane meniscus formed in an axisymmetric experimental setup as described in [17] is studied. Axial symmetry leads to the construction of the computational domain along one radius as shown schematically in Fig. 2a. As seen in Fig. 2b, the vertical space between two concentric disks forms the channel of interest. The lower disk is a $38.1 \mathrm{~mm}$ radius, $500 \mu \mathrm{m}$ thick fused quartz wafer, while the upper disk is made of acrylic and has $29.21 \mathrm{~mm}$ outer radius and 
$5.08 \mathrm{~mm}$ thickness. A constant heat flux is provided using a $100 \mathrm{~nm}$ titanium layer deposited on the underside of the quartz wafer. The titanium heat source is annular in geometry with the annulus inner and outer radii being $29.21 \mathrm{~mm}$ and $38.1 \mathrm{~mm}$, respectively. Liquid continuously fed from a syringe pump enters the test piece through an inlet at the axis of the assembly, emerges from the opening at the location of the outer radius of the upper disk, and forms a meniscus right above the heat source, causing it to evaporate into the atmosphere. The meniscus so formed is shown in Fig. 2c and has two solid-liquid-vapor junctions, one on the quartz wafer below referred to as the contact line in this work, and the other at the edge of the acrylic top piece. The experimentally obtained meniscus images are digitally processed using an edge-detection algorithm in MATLAB [19]. Since the spatial resolution of the meniscus image is $4 \mu \mathrm{m}$, the liquid film is truncated at a thickness of $4 \mu \mathrm{m}$ as shown in the inset in Fig. 2c.

\subsection{Evaporation at the Liquid-Vapor Interface}

Schrage [20] proposed a theory for evaporation at liquid-vapor interfaces in which the net mass flux across the interface is given by

$$
m_{\text {evap }}^{\prime \prime}=\frac{2 \bar{\sigma}}{2-\bar{\sigma}}\left(\frac{\bar{M}}{2 \pi \bar{R}}\right)^{1 / 2}\left(\frac{p_{v_{-} e q u}\left(T_{l v}\right)}{T_{l v}^{1 / 2}}-\frac{p_{v_{-} l v}}{T_{v_{-} l v}^{1 / 2}}\right)
$$

Assuming the interface temperature to be equal to the vapor temperature near the interface [21], Eq. (1) becomes

$$
m_{\text {evap }}^{\prime \prime}=\frac{2 \bar{\sigma}}{2-\bar{\sigma}}\left(\frac{\bar{M}}{2 \pi \bar{R}}\right)^{1 / 2} \frac{1}{T_{l v}^{1 / 2}}\left(p_{v_{-} e q u}\left(T_{l v}\right)-p_{v_{-} l v}\right)
$$

Disjoining pressure effects [21] are ignored. The equilibrium vapor pressure is approximated by the saturation pressure $P_{s a t}\left(T_{l v}\right)$ estimated by the Clausius-Clapeyron equation. This gives

$$
p_{v_{-} e q u}\left(T_{l v}\right) \approx p_{\text {sat }}\left(T_{l v}\right)=p_{s a t_{2} r e f} \exp \left(\frac{\bar{M} h_{f g}}{\bar{R}}\left(\frac{1}{T_{\text {sat_ref }}}-\frac{1}{T_{l v}}\right)\right)
$$

\subsection{Vapor Transport in Air}

The gas domain is modeled as a perfect gas mixture. The species transport equation for vapor transport in air is given by

$$
0=-\vec{v} \cdot \nabla C_{v}+\nabla \cdot\left(D \nabla C_{v}\right)
$$


The first term on the right side is the convection component due to bulk motion of gas, and the second term is the diffusion component. The mass flux at the interface may be obtained as

$$
m_{v}^{\prime \prime}=M \cdot J=\left.M \cdot\left(-D \frac{\partial C_{v}}{\partial n}+v_{n} C_{v}\right)\right|_{l v}
$$

where the first and second terms on the right account for the diffusion and convection, respectively. A similar equation can be written for air and since at the interface there is no air diffusion, the normal velocity $v_{n}$ can be obtained by setting $m_{\text {air }}^{\prime \prime}=0$

$$
\left.v_{n}\right|_{l v}=\left.\frac{1}{C_{a i r}} \cdot D \frac{\partial C_{a i r}}{\partial n}\right|_{l v}=-\left.\frac{1}{C_{\text {total }}-C_{v}} \cdot D \frac{\partial C_{v}}{\partial n}\right|_{l v}
$$

Substituting $v_{n}$ in the mass flux equation (5), the mass flux at the interface due to the vapor transport is given by

$$
m_{v}^{\prime \prime}=m_{d i f f}^{\prime \prime} \frac{C_{g}}{C_{g}-\left(\left.C_{v}\right|_{l v}\right)}
$$

The vapor molar concentration at the interface $\left.C_{v}\right|_{l v}$ is determined from $p_{v_{-} l v}$ under the ideal gas assumption

$$
\left.C_{v}\right|_{l v}=\frac{p_{v_{-} l v}}{p_{a t m}} \cdot C_{g}
$$

where the total gas molar concentration $C_{g}$ is given by

$$
C_{g}=\frac{p_{a t m}}{R T_{l v}}
$$

The vapor transport estimated from $\mathrm{Eq}$ (7) must be equal to evaporation mass flux, i.e., $m_{\text {evap }}^{\prime \prime}=m_{v}^{\prime \prime}$. Therefore, combining Eq.(2) and Eq.(7) gives

$$
p_{v_{-} l v}=p_{v_{-} e q u}\left(T_{l v}\right)-\frac{m{ }_{v}}{\frac{2 \bar{\sigma}}{2-\bar{\sigma}}\left(\frac{\bar{M}}{2 \pi \bar{R}}\right)^{1 / 2} \frac{1}{T_{l v}^{1 / 2}}}
$$

When evaporation occurs in a pure vapor domain, $p_{v_{-} l v}$ is fixed in Eq. (10) and the evaporation mass flux $m_{v}^{\prime \prime}$ is obtained. In the present problem, $p_{v_{-} l v}$ is an unknown and is obtained by solving the vapor transport equation. Fig. 3 illustrates the details of the iteration loop. In the CFD model, 
the vapor molar concentration, i.e., $C_{v}$ in the gas domain, is calculated with initial boundary conditions. Then the vapor mass flux at the interface $m_{v}^{\prime \prime}$ is obtained from Eq.(7). The new vapor pressure $p_{v_{-} l v}$ is then estimated using Eq.(10), and the boundary condition $\left.C_{v}\right|_{l v}$ is revised using Eq.(9) for the next round of vapor transport calculations.

\subsection{Governing Equations in Liquid and Solid Domains}

Incompressible, laminar and Newtonian flow of heptane with constant properties is assumed in the liquid domain. Thermocapillary convection due to temperature variation along the interface is also accounted for. The following continuity, momentum, and energy equations are solved:

$$
\begin{aligned}
& \nabla \cdot\left(\rho_{i} \vec{V}\right)=0 \\
& 0=-\nabla p_{i}+\nabla \cdot(\mu \nabla \vec{V})-\rho_{i} \vec{V} \cdot \nabla \vec{V} \\
& 0=-\rho_{i} \vec{V} \cdot \nabla h_{i}+\nabla \cdot\left(k_{i} \nabla T\right) \\
& i=l \text { for liquid, g for gas }
\end{aligned}
$$

The incoming liquid enters the channel as shown in Fig. 2b. It is assumed to enter at a constant temperature $T_{\text {inlet }} \sim 295 \mathrm{~K}$ and a known stagnation pressure.

In the solid domains, the quartz wafer and the acrylic top, the energy equation reduces to:

$$
\nabla^{2} T=0
$$

A heat flux boundary condition is applied to simulate the heat input to the quartz wafer as noted in Fig. $2 b$.

\subsection{Vapor/Air Domain}

Laminar Newtonian flow is assumed in the vapor/air domain. The perfect gas law is assumed to hold. This yields the density of the mixture $\rho_{g}$ as

$$
\rho_{g}=C_{v} M_{v}+\left(C_{g}-C_{v}\right) M_{a i r}
$$

The Boussinesq approximation is employed to model the natural convection in the gas domain. Accordingly, the local density is a function of local temperature $T$ and local $C_{v}$. The continuity, momentum and energy equations in Eq. (11) are solved together with the vapor transport Eq. (4) and the density expression Eq.(13). 
Since the evaporation rates are small $\left(\sim 10^{-6} \mathrm{~kg} / \mathrm{s}\right)$, the vapor molar concentration $C_{v}$ is assumed to be zero at the boundary far away from the interface while $C_{v}$ at the interface is determined by Eq.(8). The boundary conditions in the vapor/air domain are illustrated in Fig. 2a. To simulate the convection in the ambient due to air ventilation in the room, an experimentally measured air velocity of $\sim 0.2 \mathrm{~m} / \mathrm{s}$ is imposed as the boundary condition at the bottom boundary of the domain as shown in Fig 2a. The rest of the boundaries of the domain are set as stagnation pressure outlets. The temperature at all the outer boundaries is set to the room temperature of $T_{a t m}$ $\sim 295 \mathrm{~K}$.

\section{NUMERICAL ANALYSIS}

The numerical solution is obtained using the pressure-based finite volume scheme described in $[22,23]$ using heptane as the working fluid; relevant fluid properties at standard operating conditions are listed in Table 1 and Table 2. The commercial software package FLUENT [24] is used. A first order upwind differencing scheme is employed. Pressure-velocity coupling is achieved using the SIMPLE algorithm. Axial symmetry leads to the construction of the geometry shown in Fig. 2a. A pressure-outlet boundary is set at the outer boundary. The grid setup is as shown in Fig. 4. Quadrilateral elements are used in all the sub-domains. A mesh-independence study was conducted using three sets of grids as summarized in Table 3; results of the meshindependence study are shown in Table 4. Based on these results, mesh 1 was used for case 2. Similarly, appropriate meshes were chosen for case 1 and case 3 as well. A recent model developed by Wang et al. [25] showed that the amount of heat transfer taking place from the thinfilm region in a channel of dimension over $260 \mu \mathrm{m}$ is negligible. And since the thin-film region is the region that is dominated by disjoining pressure, it follows that the disjoining pressure effects are therefore small at these dimensions. As the present channel dimension is $\sim 500 \mu \mathrm{m}$, disjoining pressure effects are assumed to be minimal and are not accounted for in the present model.

Evaporation is simulated by imposing a mass sink term in the liquid domain cell adjacent to the interface and an equivalent mass source term in the vapor domain cell adjacent to the interface. A negative energy source term is employed on the liquid side to simulate the cooling effect of evaporation. These details are discussed in $[26,27]$. 


\section{RESULTS AND DISCUSSION}

The results discussed here are related to the experimental conditions of case 2 (see Fig. 1) with thermocapillary convection unless otherwise stated. The differential evaporation along the meniscus and the influence of convection in the gas domain are quantified. The predicted temperature profile and evaporation rate are compared with experimental results. The influence of thermocapillary convection on the total heat transfer from the meniscus is also discussed.

\subsection{Temperature Distribution}

Fig. 5 shows the temperature contours near the heated region. The different modes of heat transport in the domain are also indicated in the figure. A simple heat balance as follows

$$
Q_{\text {input }}=Q_{\text {evap }}+Q_{\text {sensible heat }}+Q_{\text {conv I }}+Q_{\text {conv II }}
$$

Implies that the heat input to the quartz wafer is converted to latent heat by evaporation, sensible heating of the liquid, natural convection from the exposed quartz surface and exposed acrylic top. For case $2, Q_{\text {input }}, Q_{\text {evap }}, Q_{\text {sensibleheat }}, Q_{\text {conv I }}$, and $Q_{\text {conv II }}$ are $1.87,0.34,0.03,0.1,1.4 \mathrm{~W}$ respectively. It can be seen that natural convection accounts for a bulk of the heat transfer (approximately $75 \%$ ) while the amount of sensible heat gained by the liquid (approximately 1.6\%) is nearly negligible. This points to the importance of heat loss estimates in experiments which are conducted in open-to-air ambients.

As seen in Fig. 5, the hottest region in the domain is close to edge of the wafer. The vapor/air mixture close to the heated region is lighter and rises upward. The stream traces mark this flow pattern due to natural convection, and will be discussed in detail in a later section.

\subsection{Non-uniform Vapor Diffusion Flux along the Meniscus}

Fig. 6a presents the vapor concentration $\left(\mathrm{mol} / \mathrm{m}^{3}\right)$ near the meniscus and the stream traces show the path taken by the vapor molecules generated by evaporation. The vapor molar concentration decreases from its highest value (approximately $4 \mathrm{~mol} / \mathrm{m}^{3}$ ) at the meniscus to $1 \times 10^{-6} \mathrm{~mol} / \mathrm{m}^{3}$ at the outlet; the corresponding vapor pressure drop is approximately $1.1 \times 10^{4} \mathrm{~Pa}$. It may be noted that the vapor concentration contours are denser at both the solid-liquid-vapor junctions, yielding high diffusion fluxes at both ends. This non-uniform diffusion flux along the interface leads to stronger evaporation at the junctions. This also leads to more vapor generation at the corners, as observed in Fig. 6b. The region marked with a dashed oval in this figure indicates the region of highest vapor velocity at the interface, commensurate with the high heat 
transfer efficiency of the thin-film region. While the high evaporation at the s-l-v junction near the acrylic top can be attributed mainly to the strong curvature of the meniscus, other factors may also play a role. High thermal conductance and high disjoining pressure gradient due to the small film thickness and enhanced evaporation due to the higher interface temperature (see Fig. 7) also contribute to intensive evaporation at the contact line.

Fig. 6c details the flow field in the meniscus as well as the temperature distribution shown as a contour map. The temperature gradient induced due to the differential evaporation along the meniscus drives the observed flow pattern. As seen in Fig. 6c, the local interface temperature is higher at the contact line than at the other upper corner. Since the surface tension of heptane decreases with an increase in temperature (see Table 1), the surface tension is higher at the s-1-v junction near the acrylic top than at the contact line. This drives a flow from the contact line towards the other corner, thus forming an anticlockwise vortex in a two-dimensional (2D) plane and a toroidal vortex in 3D. The maximum velocity observed in the liquid domain is approximately $0.012 \mathrm{~m} / \mathrm{s}$. This convection leads to a modest enhancement in the evaporation heat transfer as discussed in the next section.

\subsection{Effect of Thermocapillary Convection on Heat Transfer Performance}

Thermocapillary convection has long been believed to enhance heat transfer from evaporating menisci [4]. In order to characterize the effects of thermocapillary convection, a full simulation including thermocapillary convection in the liquid domain is compared with a calculation where the convection in the liquid domain is absent. Plotted in Fig. 7 is the non-dimensional liquidvapor interface temperature along the non-dimensional length of the meniscus for all three cases studied, each with and without thermocapillary convection. The interface temperature is presented in non-dimensional form as $T^{*}=\left(T_{l v}-\min \left(T_{l v}\right)\right) /\left(q " w / k_{l}\right)$, where $\min \left(T_{l v}\right)$ is the minimum temperature along the interface. Since the length of the curved surface of the meniscus is different in each case, a non-dimensional length is used in this figure. It is defined as the ratio of length along the curved surface to the total length of the meniscus, with the origin located at the s-l-v junction near the acrylic top. Thus, a value of 1 corresponds to the contact line on the heated surface as shown in Fig. 7. The maximum uncertainty in calculating $T^{*}$ estimated using a standard propagation of error analysis is found to be nearly $11.5 \%$ for the lowest heat flux to $9 \%$ for highest heat flux. Each of the three temperature profiles for thermocapillary convection and no thermocapillary convection fall in a group. In all the three cases, the minimum and temperature is recorded at the s-l-v junction near acrylic top as it is the farthest from the heat source, while the highest temperature is seen at the contact line as it is nearest to the heat source. 
For each case, the temperature gradient is higher when the thermocapillary phenomenon is absent. This illustrates that the mixing due to thermocapillary convection tends to reduce the temperature gradient. As discussed earlier in Fig. 6c, the hot liquid present near the contact line is pulled towards the acrylic top thus increasing the local temperature near the junction. The average interface temperature is higher when the thermocapillary phenomenon is present.

The local evaporative mass flux is plotted as a function of non-dimensional distance along the meniscus for all three cases in Fig. 8. The thin-film region near the contact line has the highest local mass flux and a second peak is noted at the junction near the acrylic top for all three cases. The high vapor diffusive fluxes near the junctions seen in Fig. 6a give rise to these peaks. The increase in local mass fluxes with an increase in the applied heat flux are also observed. While thermocapillary convection has a rather minor influence on the evaporative fluxes, the local evaporative fluxes are somewhat enhanced near the contact line and suppressed near the acrylic top junction when the thermocapillary phenomenon is absent. This trend is similar to the interface temperature behavior noticed above and results from the higher local heat flux due to the higher interface temperature.

The predicted evaporation rates from the menisci are compared with the experimental values in Fig. 9. For any given case, the evaporation rate for the full simulation including thermocapillary convection is higher compared to the no convection case. However, this increase varies only from $2.1 \%$ for the low heat flux case to $3.6 \%$ for the high heat flux case. A similar result was reported in [12] where the augmentation of heat transfer due to convection was only 3$5 \%$ for superheats below $5 \mathrm{~K}$. For case 2, the Peclet number $(\mathrm{Pe} \sim \mathrm{Vw} / \mathrm{\kappa})$ is approximately 145 . At this modest value of Peclet number, the flow is seen to modestly influence the interface temperature as seen in Fig. 7. The enhancement in heat transfer is minor because of the relatively low applied heat fluxes. Higher heat fluxes could not be achieved in the experiments because of instability of the contact line. It is postulated that at higher heat fluxes, thermocapillary convection effects would be greater.

It can be seen that the model overpredicts the experimental evaporation rates in all three cases by nearly $\sim 20 \%$. The experimental uncertainty in evaporation rate measurement is very small ( $0.035 \%$ ). This discrepancy may be attributed to an inadequate measurement of the air circulation velocity in the room. A larger discrepancy can also be noted with increasing heat flux, which indicates that the uncertainty in accounting for heat losses in the system. The uncertainty in air velocity measurement is $\sim 25 \%$ which corresponds to a change in mass transfer of $5 \%$. Since the heat losses constitute to bulk of the heat input ( $75 \%)$, a $1 \%$ error in heat loss estimation 
corresponds to a $3 \%$ change in mass transfer. Thus, the mass transfer calculation is most sensitive to the heat loss estimates.

Thermocapillary convection has been shown [4] to induce instabilities near the interface at higher evaporation rates. In the present work, due to the low evaporation rates, there is negligible convection in the liquid. Thus the capillary number defined as the ratio of viscous to surface tension forces $C a=\mu V / \sigma$ is $10^{-5}$ and Weber number defined as the ratio of inertial to surface tension forces $W e=\rho V^{2} L / \sigma$ is $10^{-3}$. This shows that the surface tension force is significantly higher than inertial and viscous forces and thus, a static interface profile may be assumed for low evaporation rates. In the literature, the Marangoni number, defined as $M a=(d \sigma / d T)(\nabla T) L^{2} / \mu \alpha$, has been used to characterize thermocapillary convection. In the present case, $M a \sim 15000$ for $L \sim 10^{-3}$ and $\Delta T \sim 4 \mathrm{~K}$.

\subsection{Wall Temperature Near the Thin-film Region}

Fig. 10 presents the experimental and predicted temperature profiles of the wall in a small region near the contact line. It can be seen that the predicted temperature is within the error limits of the measured values and the disagreement increases with increasing heat flux. Another important trend to note is the difference in the profiles of the measured and predicted temperatures. While the measured values show a small temperature dip $\sim 0.5 \mathrm{~K}$ at the contact line indicating local cooling due to thin-film evaporation, the calculated profiles are largely linear and indicate no such dip. No dip was computed even in the absence of thermocapillary convection. This disparity is attributable to the region below $4 \mu \mathrm{m}$ thickness being neglected in the simulations, as noted earlier. It is known that thinner films have lower thermal resistance and hence give rise to larger evaporative mass fluxes and more cooling near the interface. Therefore, in the present work, the predicted evaporative mass fluxes near the contact line may not have been high enough to induce a temperature dip. Future work will include this truncated region.

\subsection{Role of Convection in Species Transport}

As mentioned earlier, the density in the gas domain is a function of local vapor concentration and local temperature. Fig. 11a shows the density distribution in the gas domain near the heat source. Since heptane vapor is heavier than air, the vapor/air mixture density varies from a maximum of $4 \mathrm{~kg} / \mathrm{m}^{3}$ at the interface to a minimum of approximately $1 \mathrm{~kg} / \mathrm{m}^{3}$ on the underside of the wafer. The interface has the maximum gas density because it is the location of highest 
concentration of evaporated heptane vapor (see Fig. 6a). Since density of both heptane vapor and air decrease with an increase in temperature, the vapor/air mixture near the heat source is lighter.

Fig. $11 \mathrm{~b}$ depicts the convective flow in the gas domain. Because of the variation in the density and the forced flow from the bottom surface, a large recirculation zone is observed near the acrylic top. The resulting Peclet number based on the length of the heat source is 54 . To quantify the importance of flow on the species transport equation, results obtained by solving only for diffusion are compared to the complete simulation. The evaporation rate obtained by solving only for diffusion underpredicts the mass transport by nearly $7.7 \%$. This outlines the effect of flow in the gas domain on evaporative heat transfer. A smaller vortex was observed in the case when there is no forced flow from the bottom surface (results not shown). This effect could be significant in applications such as micro heat pipes where the gas velocities are higher.

\section{CONCLUSIONS}

A numerical model is developed for evaporation from a steady, liquid-vapor interface into air formed in a channel spacing of $500 \mu \mathrm{m}$. The meniscus profile and appropriate boundary conditions obtained from the experiments are used as inputs to the model and the predicted evaporation rates are compared against the experimental values. Evaporation at the interface and the vapor transport process in the gas domain are solved in an iterative manner to obtain the flow and temperature maps in the liquid and vapor domain. The importance of convection in the species transport equation is outlined. It is shown that neglecting convection in the species transport would somewhat underestimate the heat and mass transfer. The numerical model is validated against three different experimental cases and is found to agree within $20 \%$ of the experimental values. The high vapor diffusion fluxes near the contact line demonstrate the strength of thin-film evaporation. Thermocapillary convection generated due to this differential evaporation is characterized by comparing it to a simulation where convection is absent. This showed that the local interface temperature and the local evaporative fluxes are mildly enhanced near the contact line and moderately suppressed further away. Thermocapillary convection is shown to contribute to only $4 \%$ of the heat transport.

This experimentally validated model may be used to evaluate the evaporation rate from any static liquid-vapor interface under saturated or open-to-air conditions. This model may also be included in the numerical models of two-phase devices and can be used to optimize wick structures for better heat transfer performance. 


\section{LIST OF TABLES}

Table 1. Fluid properties.

Table 2. Solid properties.

Table 3. Specification of meshes used in the mesh-independence study.

Table 4. Mesh-Independence Results.

\section{LIST OF TABLES}

Fig. 1 Two-dimensional meniscus images obtained from experiments: (a) Case 1, Evaporation rate $(\dot{m})=8.8 \times 10^{-7} \mathrm{~kg} / \mathrm{s}$ and heat flux $\left(q^{\prime \prime}\right)=810 \mathrm{~W} / \mathrm{m}^{2}$, (b) Case 2, $\dot{m}=8.4 \times 10^{-7} \mathrm{~kg} / \mathrm{s}$ and $q^{\prime \prime}=990 \mathrm{~W} / \mathrm{m}^{2}$, and (c) Case $3, \dot{m}=9.4 \times 10^{-7} \mathrm{~kg} / \mathrm{s}$ and $q^{\prime \prime}$ $=1190 \mathrm{~W} / \mathrm{m}^{2}$.

Fig. 2 (a) Schematic representation of the computation domain for the axisymmetric problem with the imposed boundary conditions (BCs); (b) expanded view of the test setup with BCs; and (c) expanded view of the meniscus. The inset shows the truncation at the triple line and also the mesh structure.

Fig. 3 Iteration loop for mass flow calculation.

Fig. 4 Mesh setups: (a) total domain, (b) region near the meniscus, and (c) region near the contact line.

Fig. 5 Temperature contour $(\mathrm{K})$ and stream traces indicating the flow in the vapor/air domain. Different modes of heat transport are indicated.

Fig. 6 (a) Contour of heptane vapor concentration $C_{v}\left(\mathrm{~mol} / \mathrm{m}^{3}\right)$ near the meniscus. (b) Velocity contours $(\mathrm{m} / \mathrm{s})$ in the vapor/air domain. The highlighted region marks the highest velocity region along the interface. (c) Temperature contours (K) and stream traces showing thermocapillary convection in the meniscus.

Fig. 7 Interface temperature as a function of dimensionless length along the meniscus with its origin located at the acrylic top and other end located at the contact line.

Fig. 8 Local evaporative mass flux as a function of non-dimensional length along the meniscus.

Fig. 9 Comparison of the predicted evaporation rates with the experimental values.

Fig. 10 Wall temperature profiles near the contact line.

Fig. 11 (a) Contours of density $\left(\mathrm{kg} / \mathrm{m}^{3}\right)$ in the vapor domain near the heat source, and (b) contours of density $\left(\mathrm{kg} / \mathrm{m}^{3}\right)$ in the vapor/air domain with streamtraces. 
Table 1. Fluid properties.

\begin{tabular}{lcc}
\hline Property & Heptane & Air \\
\hline Density $\left(\mathrm{kg} / \mathrm{m}^{3}\right)$ & 666.95 at $294.65 \mathrm{~K}$ & defined by Eq. $(12)$ \\
Thermal conductivity $(\mathrm{W} / \mathrm{m} \mathrm{K})$ & 0.12746 & 0.0242 \\
Thermal capacity $(\mathrm{J} / \mathrm{kg})$ & 2298.4 & 1006.43 \\
Viscosity $(\mathrm{kg} / \mathrm{m} \mathrm{s})$ & 0.000331 & $1.789 \times 10^{-5}$ \\
Vapor molecular weight & 100 & 29 \\
Thermal expansion coefficient & 0.00128 & $/$ \\
$\mathrm{d} \sigma / \mathrm{dT}(\mathrm{N} / \mathrm{m} \mathrm{K})(313 \mathrm{~K}$ to $323 \mathrm{~K})$ & -0.000103 & $/$ \\
Vapor diffusion coefficient in air $\left(\mathrm{m}^{2} / \mathrm{s}\right)$ & $7.11 \times 10^{-6}$ at $291.2 \mathrm{~K}$ & $/$ \\
Accommodation coefficient & 1 & $/$ \\
Evaporation latent heat $(\mathrm{J} / \mathrm{kg})$ & $3.506 \times 10^{5}$ & $/$ \\
Saturated vapor pressure $(\mathrm{Pa})$ & 5316 at $295.45 \mathrm{~K}$ & \\
\hline
\end{tabular}


Table 2. Solid properties.

\begin{tabular}{lcc}
\hline Property & Fused quartz & Acrylic \\
\hline Density $\left(\mathrm{kg} / \mathrm{m}^{3}\right)$ & 2200 & 1200 \\
Thermal conductivity $(\mathrm{W} / \mathrm{m} \mathrm{K})$ & 1.4 & 0.4 \\
Specific heat capacity $(\mathrm{J} / \mathrm{kg})$ & 670 & 750
\end{tabular}


Table 3. Specification of meshes used in the mesh-independence study.

\begin{tabular}{|c|c|c|c|}
\hline & Mesh 1 & Mesh 2 & Mesh 3 \\
\hline Faces on meniscus & 224 & 183 & 150 \\
\hline Cells in liquid (Quad) & 3548 & 2465 & 1735 \\
\hline Cells in vapor (Quad) & 46667 & 30633 & 20232 \\
\hline Cells in solid (Quad) & 8829 & 5536 & 4092 \\
\hline
\end{tabular}


Table 4. Mesh-Independence Results.

\begin{tabular}{|c|c|c|c|}
\hline & Mesh 1 & Mesh 2 & Mesh 3 \\
\hline Average meniscus temperature (K) & 309.55 & 309.10 & 308.45 \\
\hline Deviation from Mesh 1 & - & $0.12 \%$ & $0.36 \%$ \\
\hline Mass flow rate $\left(10^{-7} \mathrm{~kg} / \mathrm{s}\right)$ & 9.64 & 9.54 & 9.31 \\
\hline Deviation from Mesh 1 & - & $1.11 \%$ & $3.43 \%$ \\
\hline
\end{tabular}




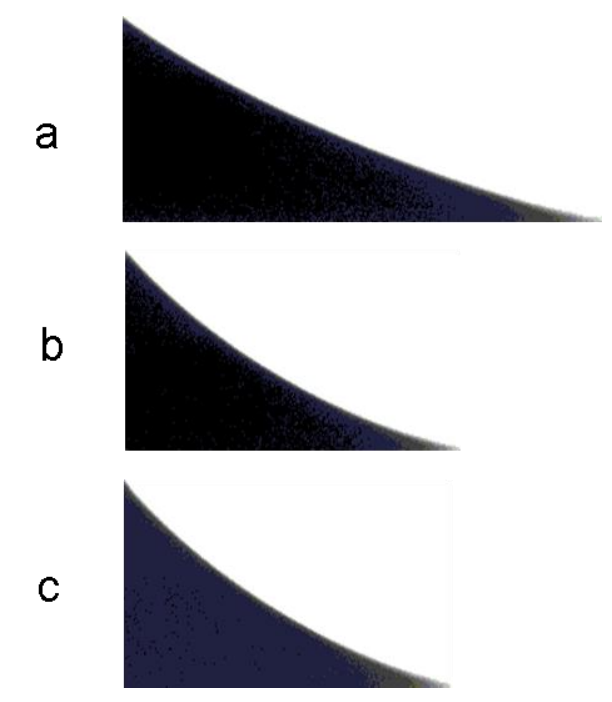

Fig. 1 Two-dimensional meniscus images obtained from experiments: (a) Case 1, Evaporation rate $(\dot{m})=8.8 \times 10^{-7} \mathrm{~kg} / \mathrm{s}$ and heat flux $\left(q^{\prime \prime}\right)=810 \mathrm{~W} / \mathrm{m}^{2}$, (b) Case $2, \dot{m}=8.4 \times 10^{-7} \mathrm{~kg} / \mathrm{s}$ and $q^{\prime \prime}$ $=990 \mathrm{~W} / \mathrm{m}^{2}$, and (c) Case $3, \dot{m}=9.4 \times 10^{-7} \mathrm{~kg} / \mathrm{s}$ and $q^{\prime \prime}=1190 \mathrm{~W} / \mathrm{m}^{2}$. 


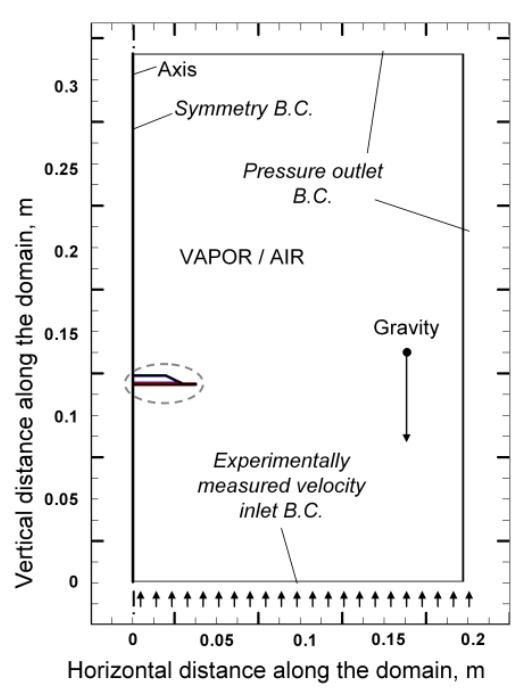

(a)

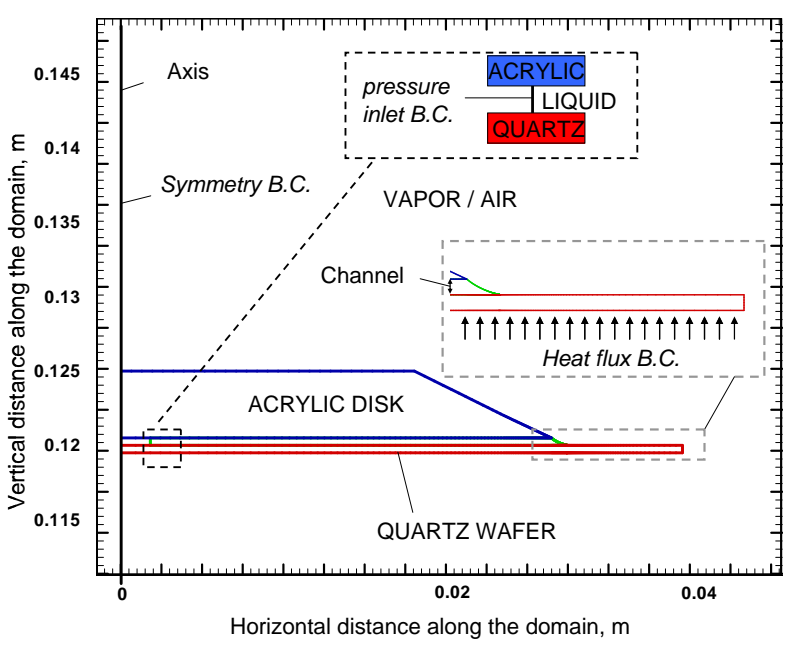

(b)

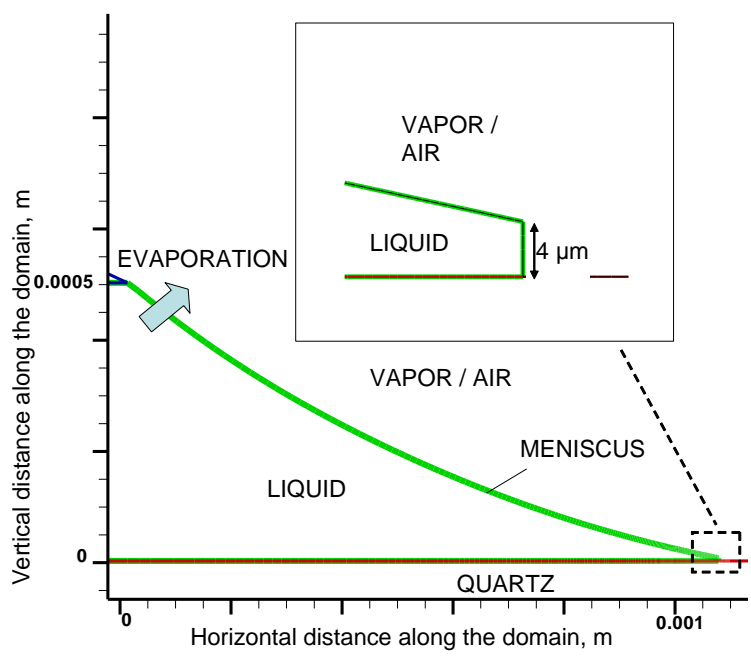

(c)

Fig. 2 (a) Schematic representation of the computation domain for the axisymmetric problem with the imposed boundary conditions (BCs); (b) expanded view of the test setup with BCs; and (c) expanded view of the meniscus. The inset shows the truncation at the triple line and also the mesh structure. 


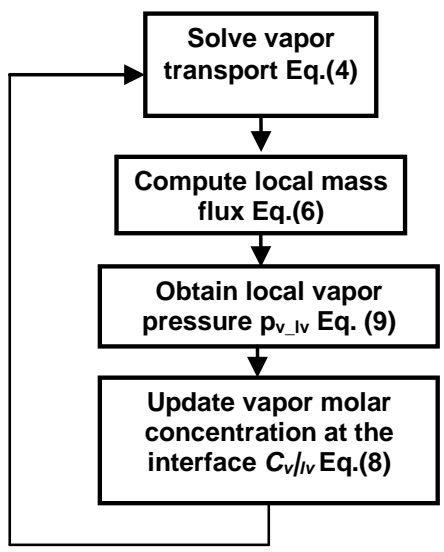

Fig. 3 Iteration loop for mass flow calculation. 


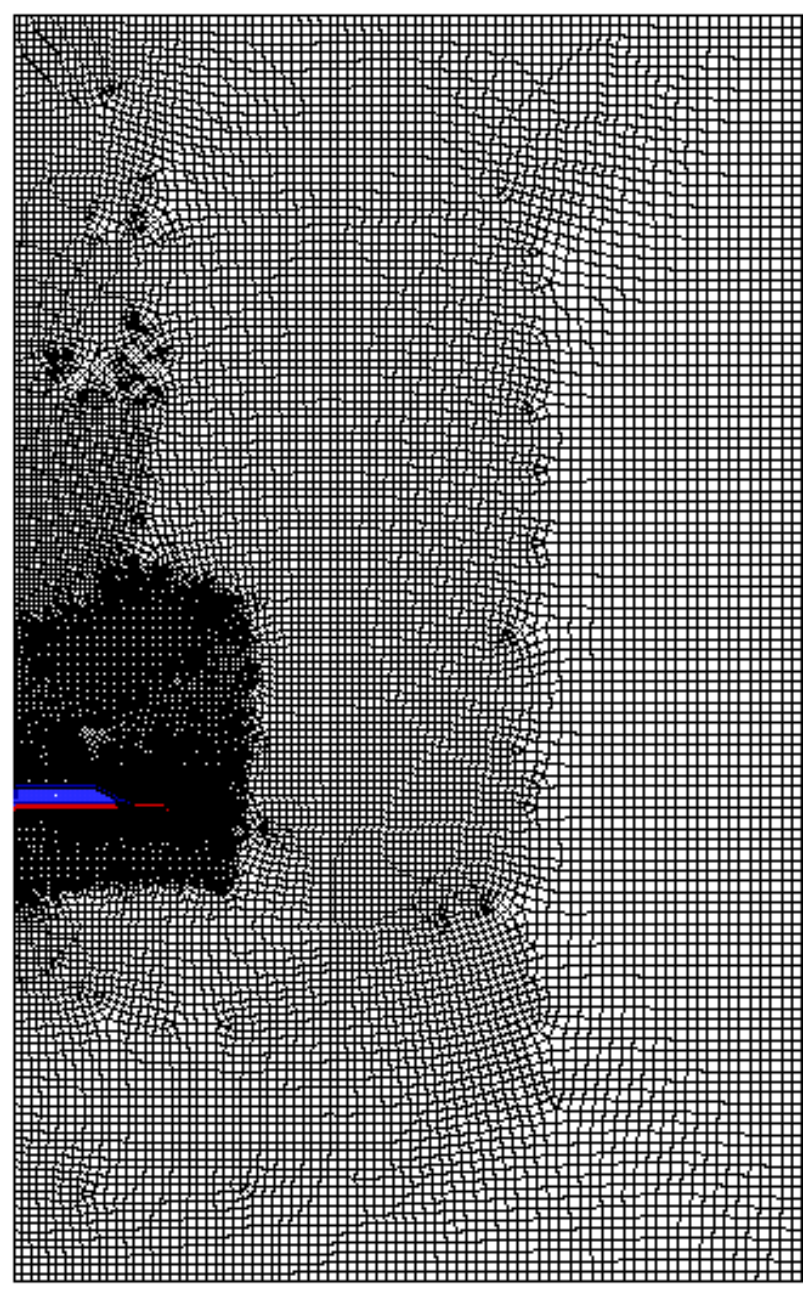

a
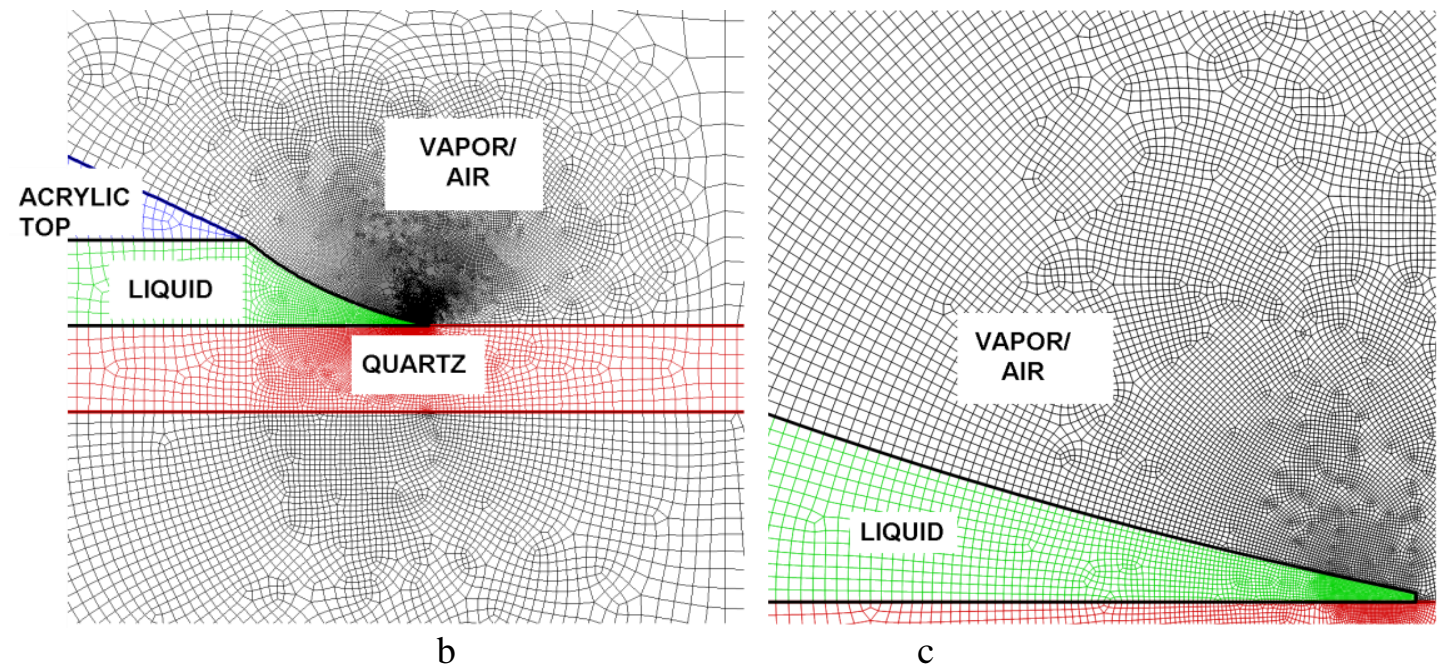

$\mathrm{C}$

Fig. 4 Mesh setups: (a) total domain, (b) region near the meniscus, and (c) region near the contact line. 


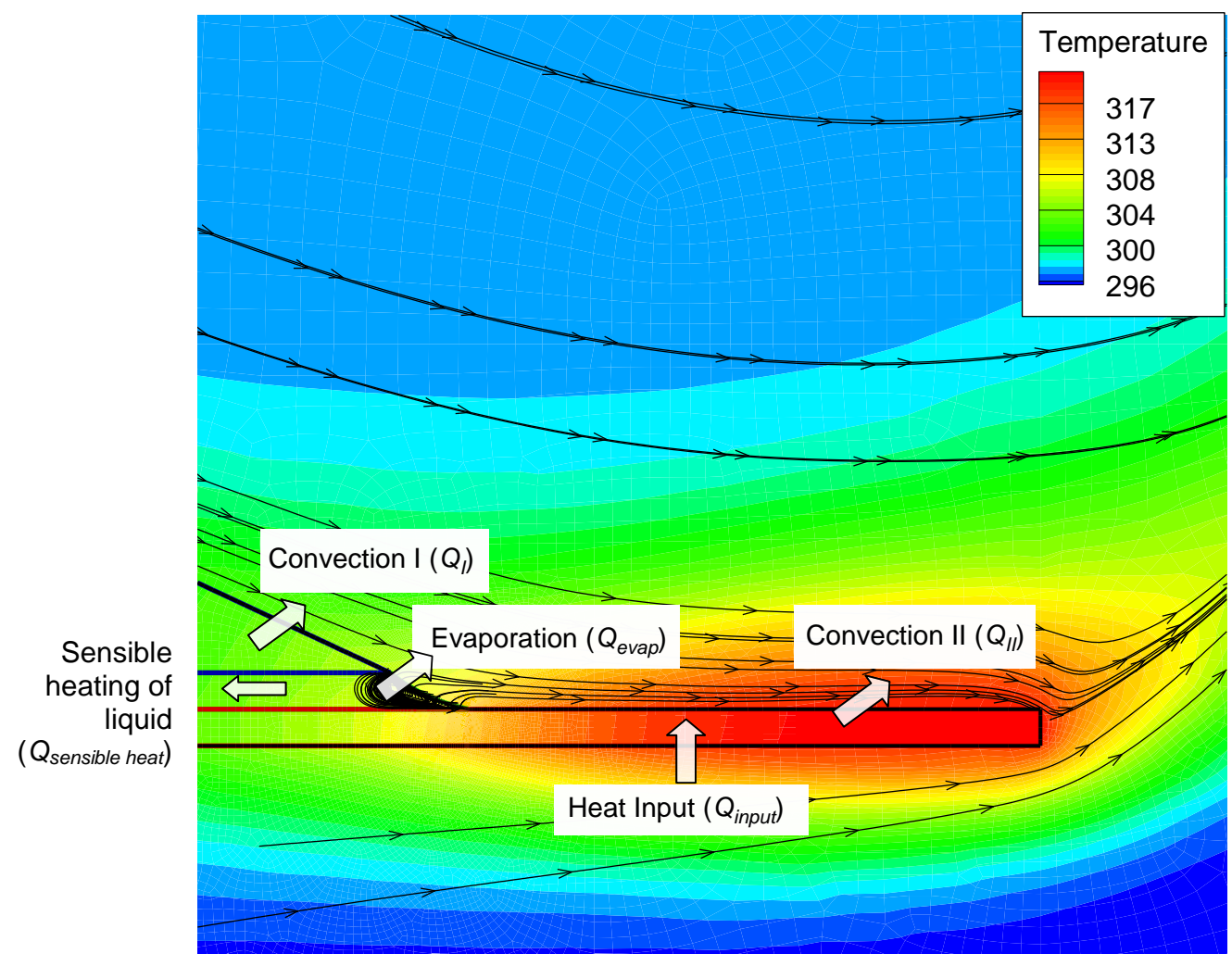

Fig. 5 Temperature contours $(\mathrm{K})$ and stream traces indicating the flow in the vapor/air domain. Different modes of heat transport are indicated. 


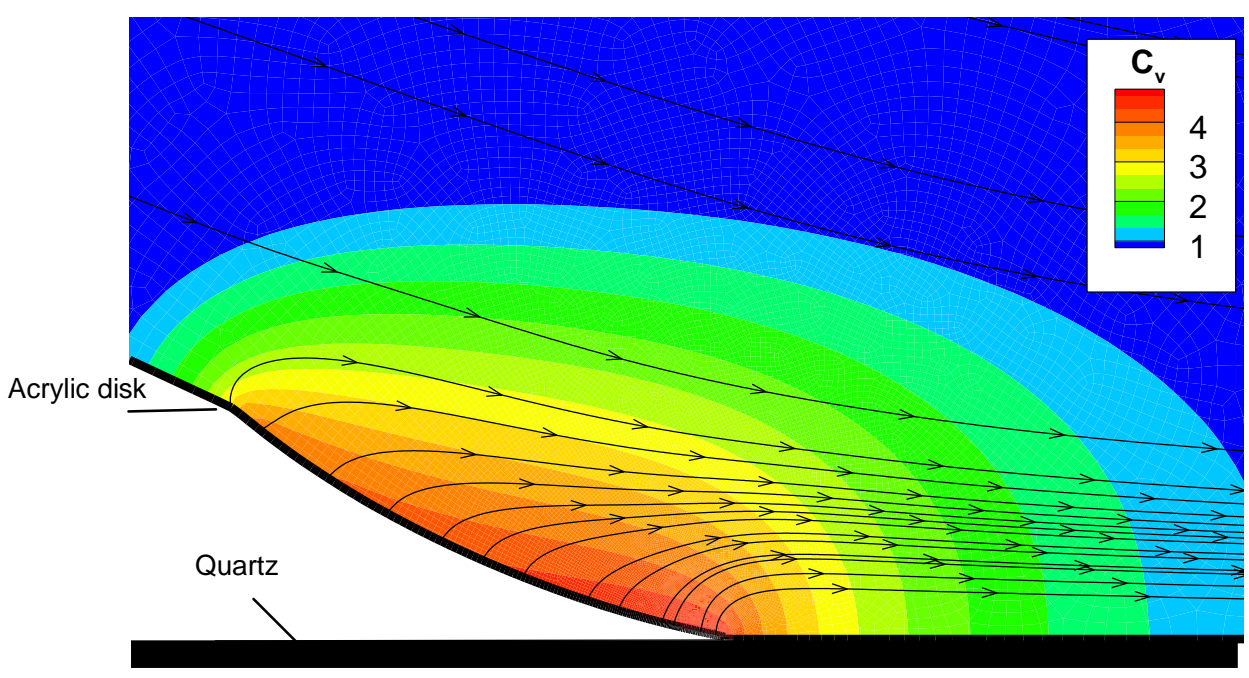

$\mathrm{a}$
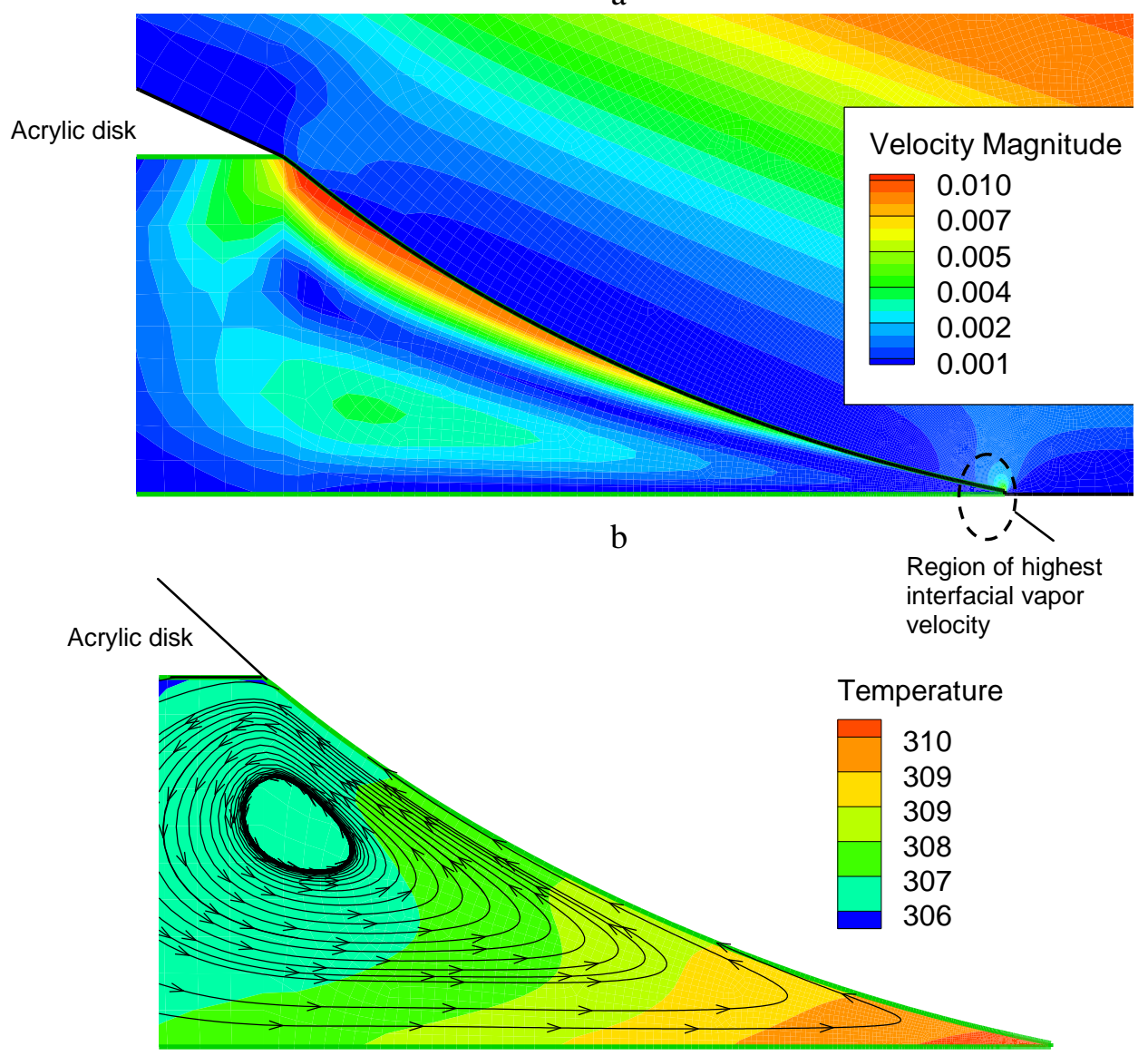

c

Fig. 6 (a) Contour of heptane vapor concentration $C_{v}\left(\mathrm{~mol} / \mathrm{m}^{3}\right)$ near the meniscus. (b) Velocity contours $(\mathrm{m} / \mathrm{s})$ in the vapor/air domain. The highlighted region marks the highest velocity region along the interface. (c) Temperature contours (K) and stream traces showing thermocapillary convection in the meniscus. 


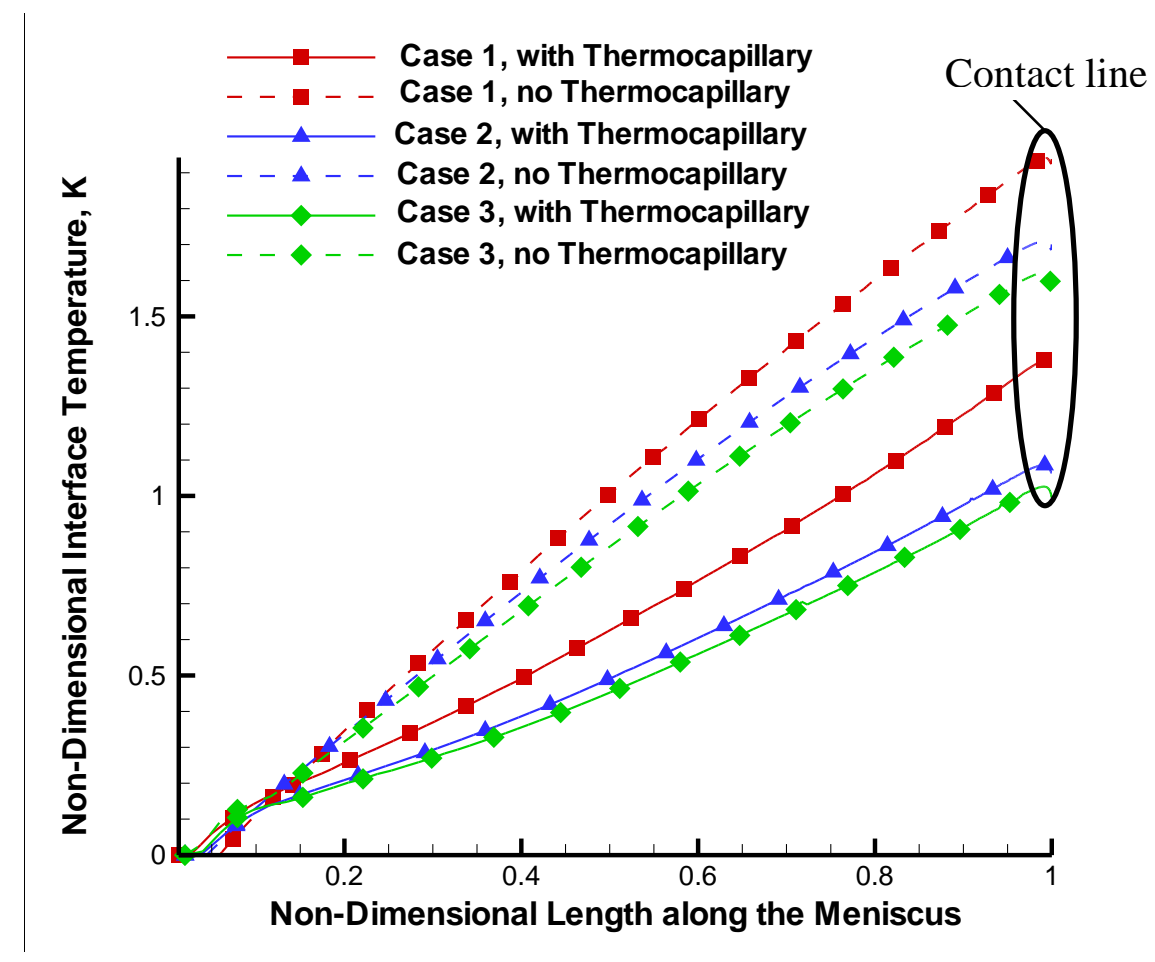

Fig. 7 Interface temperature as a function of dimensionless length along the meniscus with its origin located at the acrylic top and other end located at the contact line. 


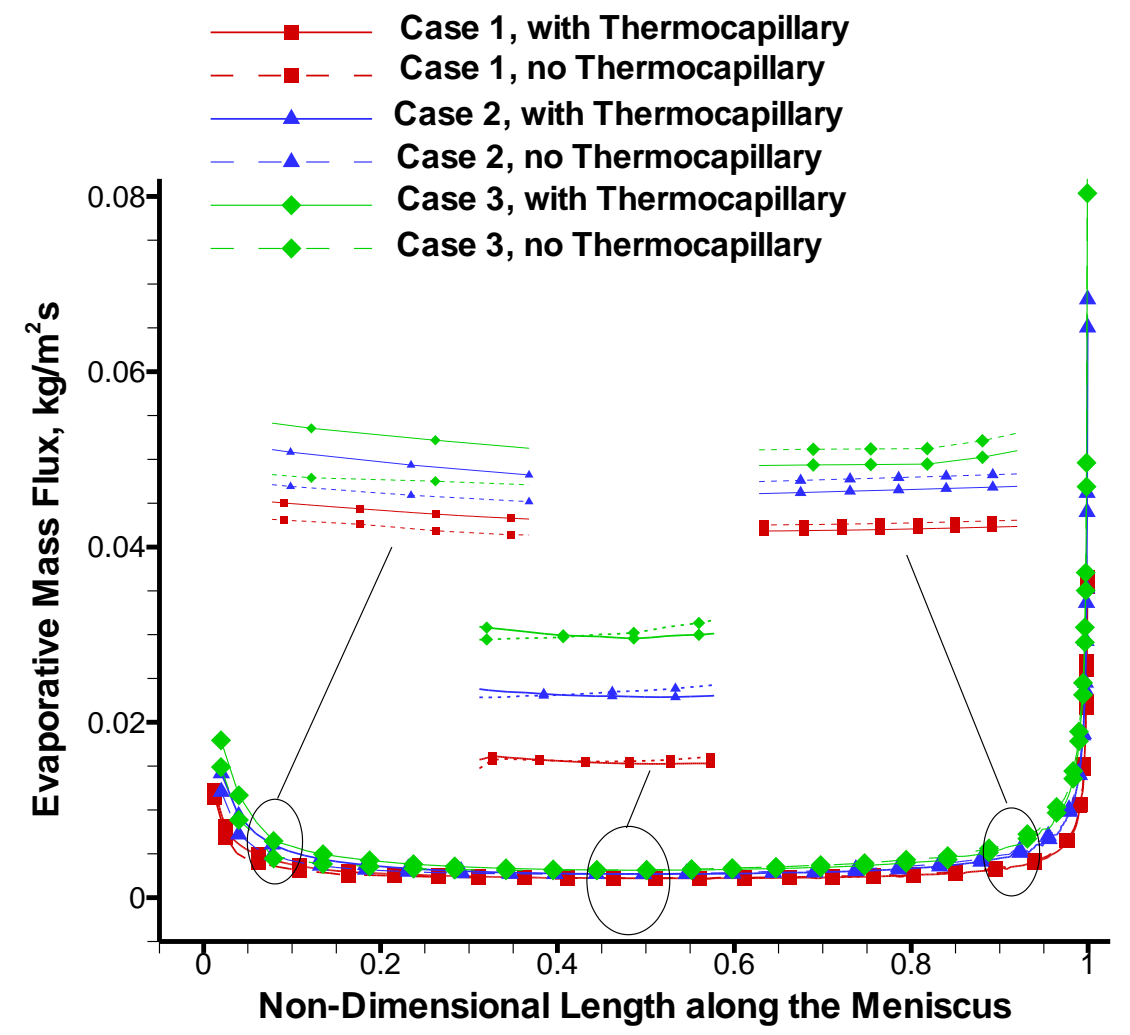

Fig. 8 Local evaporative mass flux as a function of non-dimensional length along the meniscus. 


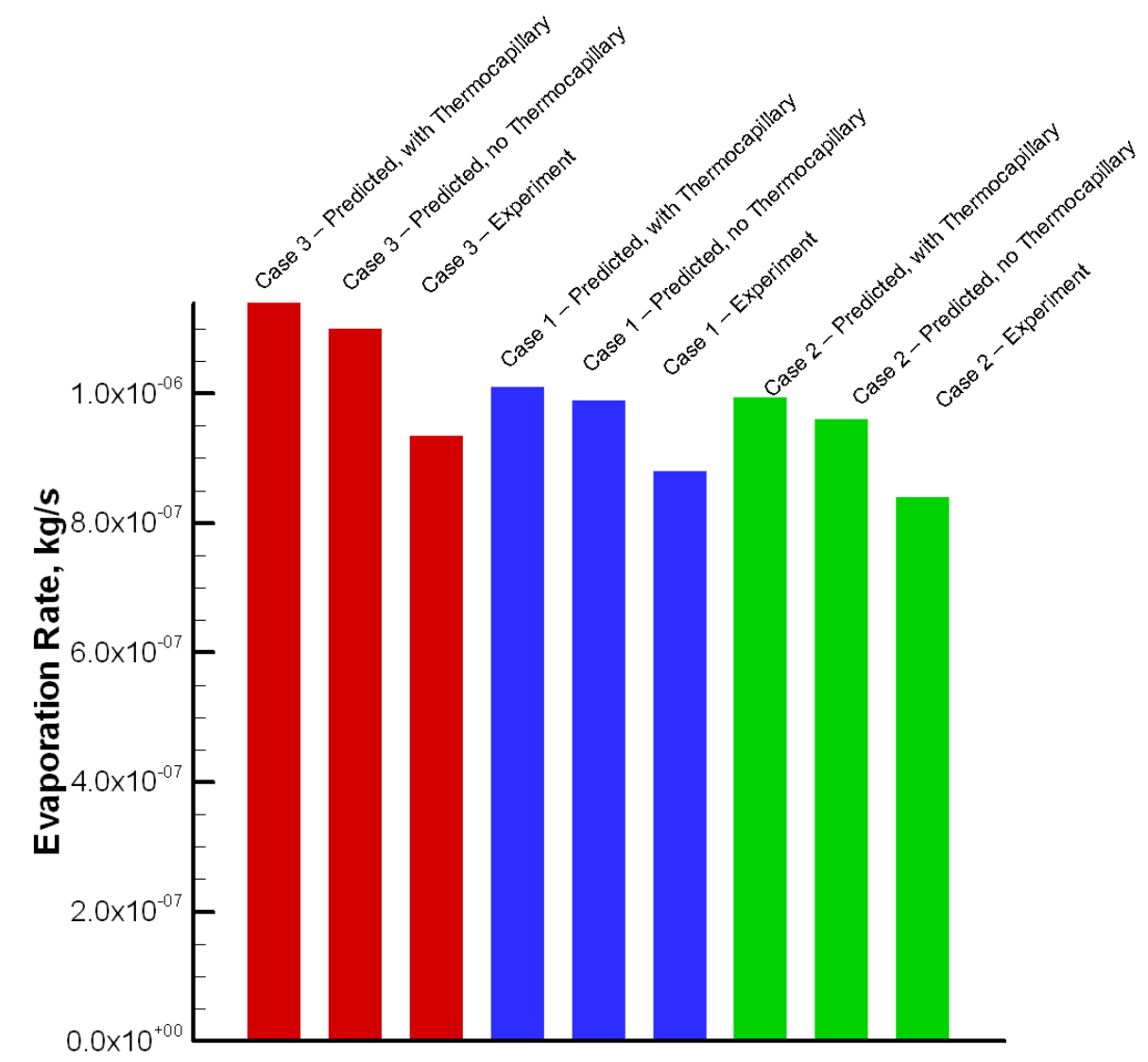

Fig. 9 Comparison of the predicted evaporation rates with the experimental values. 


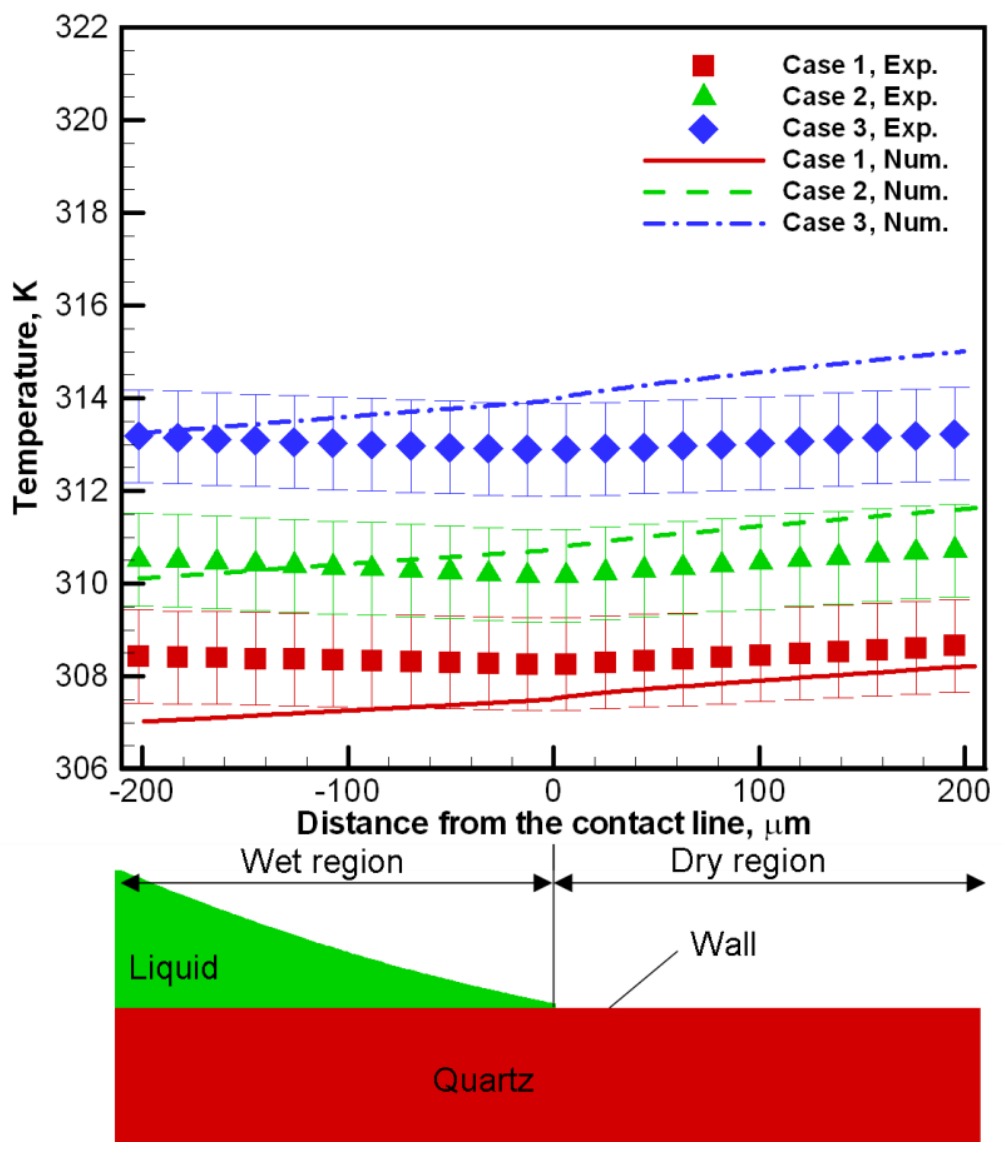

Fig. 10 Wall temperature profiles near the contact line. 


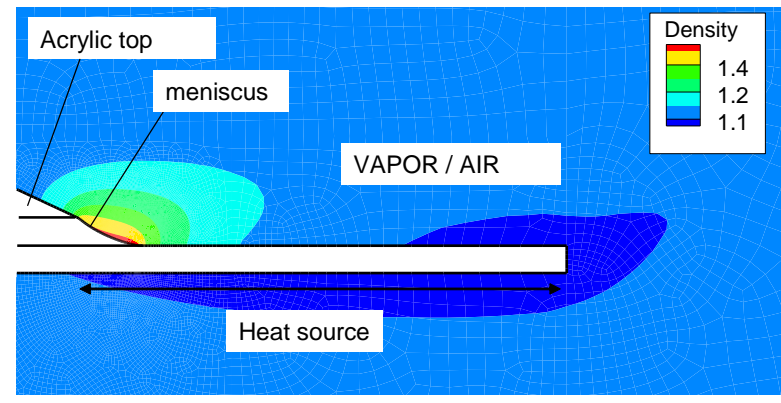

a

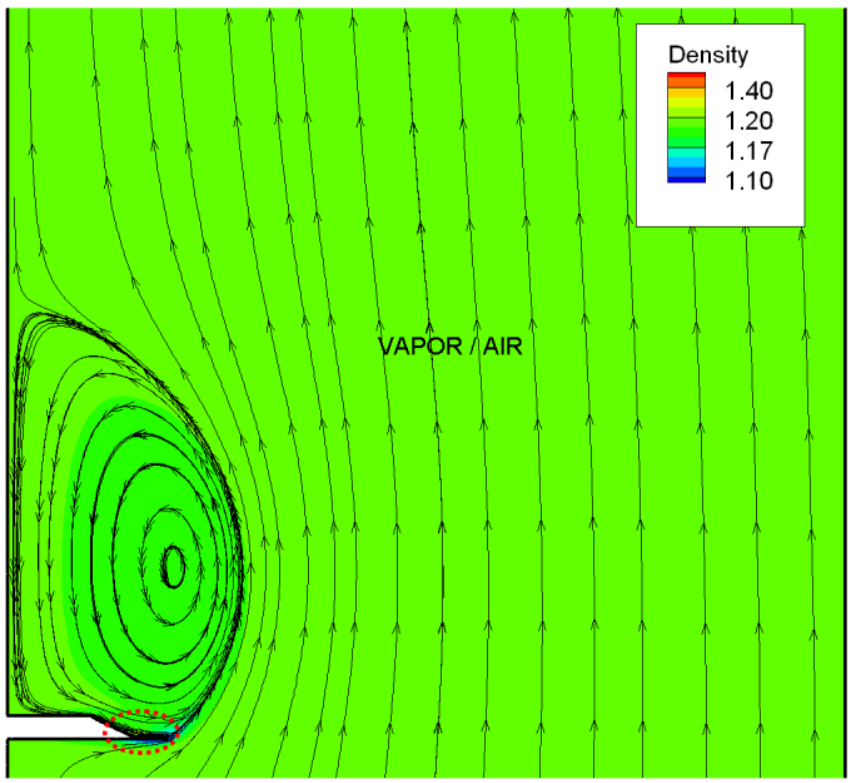

b

Fig. 11 (a) Contours of density $\left(\mathrm{kg} / \mathrm{m}^{3}\right)$ in the vapor domain near the heat source, and (b) contours of density $\left(\mathrm{kg} / \mathrm{m}^{3}\right)$ in the vapor/air domain with streamtraces. 


\section{References}

[1] A. G. Yiotis, A. G. Boudouvis, A. K. Stubos, I. N. Tsimpanogiannis, and Y. C. Yortsos, Effect of liquid films on the isothermal drying of porous media, Phys. Rev. E 68 (2003) 037303.

[2] M. Potash Jr., and P. C. Wayner Jr., Evaporation from a two-dimensional extended meniscus, Int. J. Heat Mass Transfer 15 (1972) 1851-1863.

[3] B. V. Derjaguin, Definition and the concept of and magnitude of the disjoining pressure and its role in the statics and kinetics of thin layers of liquids, Colloid J. USSR, 17 (1955) 191197.

[4] C. A. Ward, and F. Duan, Turbulent transition of thermocapillary flow induced by water evaporation Phys. Rev. E 69 (2004) 056308.

[5] H. K. Dhavaleswarapu, P. Chamarthy, S. V. Garimella, and J. Y. Murthy, Experimental investigation of steady buoyant-thermocapillary convection near an evaporating meniscus, Phys. Fluids 19 (2007) 082103.

[6] P. C. Wayner, Intermolecular forces in phase-change heat transfer: 1998 Kern award review, AIChE J. 45 (1999) 2055-2068.

[7] X. Xu, and V. P. Carey, Film evaporation from a microgrooved surface-an approximate heat transfer model and its comparison with experimental data, J. Thermophys. Heat Transfer, 4 (1990) 512-520.

[8] S. M. Demsky, and H. B. Ma, Thin film evaporation on a curved surface, Microscale Thermophysical Eng. 8 (2004) 285-299.

[9] K. Park, and K. Lee, 2003, Prediction of the transport phenomena in the micro capillary tube of a CPL system, ASME International Mechanical Engineering Congress, Washington, D.C.

[10] P. C. Stephan, and C. A. Busse, Analysis of the heat transfer coefficient of grooved heat pipe evaporator walls, Int. J. Heat Mass Transfer 35 (1992) 383-391.

[11] S. Dasgupta, J. A. Schonberg, and P. C. Wayner Jr., Investigation of evaporating extended meniscus with augmented Young-Laplace equation, J. Heat Transfer 115 (1993) 201-208.

[12] D. Khrustalev, A. Faghri, Heat transfer during evaporation on capillary-grooved structures of heat pipes, ASME J. Heat Transfer 117 (1995) 740-747.

[13] J. Jiang, Y.-X. Tao, and L. Byrd, "Evaporative heat transfer from thin liquid film on a heated cylinder, Int. J. Heat Mass Transfer 43(2000) 85-99.

[14] J. Rice and A. Faghri, Analysis of the Marangoni effect in volatile liquids evaporation from capillary tubes using a new interface tracking method, Numer. Heat Transfer, Part A, 51 (2007), 445-468. 
[15] O. E. Ruiz and W. Z. Black, Evaporation of water droplets placed on a heated horizontal surface, J. Heat Transfer 124 (2002) 854.

[16] G. Strotos, M. Gavaises, A. Theodorakakos, and G. Bergeles, Numerical investigation on the evaporation of droplets depositing on heated surface at low Weber numbers, Int. J. Heat Mass Transfer 51 (2008) 1516-1529.

[17] H. K. Dhavaleswarapu, S. V. Garimella, and J. Y. Murthy, Microscale temperature measurements near the triple line of an evaporating thin liquid film, J. Heat Transfer 131 (2009) 061501.

[18] H. Wang, J.Y. Murthy and S. V. Garimella, Transport from a volatile meniscus in a microtube, Int. J. Heat Mass Transfer 51 (2008) 3007-3017.

[19] 2007, MATLAB, The language of technical computing, version 7.1, The Mathworks Inc., Natick, MA.

[20] R. W. Schrage, A theoretical study of interface mass transfer, Columbia University Press, New York, 1953.

[21] A. Faghri, Heat Pipe Science and Technology. 1995, Washington, DC: Taylor \& Francis.

[22] S.R. Mathur, J.Y. Murthy, A pressure-based method for unstructured meshes, Numer. Heat Transfer 31 (2) (1997) 195-216.

[23] J.Y. Murthy, S. R. Mathur, A conservative numerical scheme for the energy equation, J. Heat Transfer 120 (1998) 1081-1085.

[24] Fluent Inc., Fluent 6.2 User's Guide, 2004.

[25] H. Wang, S. V. Garimella, and J. Y. Murthy, Characteristics of an evaporating thin film in a microchannel, Int. J. Heat Mass Transfer, 50 (2007) 3933-3942.

[26] D. Juric, G. Tryggvason, Computation of boiling flows, Int. J. Multiphase Flow 24 (1998) 387-410.

[27] U. Vadakkan, J. Y. Murthy and S.V. Garimella, Transient analysis of flat heat pipes, Proceedings of HT2003, 47349. 